\title{
Development of Parathyroid Adenoma in a Case of Chronic Renal Failure Suggesting Tertiary Hyperparathyroidism
}

\author{
Hiroyoshi KIKUOKA ${ }^{1}$, Masanao EMOTO ${ }^{1}$, Toshiniko YOSHIDA ${ }^{2}$, \\ KeI MIYAMURA ${ }^{1}$, TADASHI OHKAWA ${ }^{2}$, KATSUHIRO NAKAMURA ${ }^{3}$, \\ AND NoBUAKI SASANO ${ }^{4}$ \\ ${ }^{1}$ Division of Endocrinology, Department of Internal Medicine, \\ ${ }^{2}$ Department of Urology, Wakayama Medical School, Wakayama, 640 \\ ${ }^{3}$ Department of Clinical Research, Sendai National Hospital and \\ ${ }^{4}$ IInd Department of Pathology, Tohoku University School \\ of Medicine, Sendai, 980
}

\begin{abstract}
A case of tertiary hyperparathyroidism with a parathyroid adenoma and hyperplasia was described as the first report in Japan.

A 24-year-old man manifesting hypercalcemia had been treated with hemodialysis for 9 years. On admission, clubbed fingers, richitic rossaries and a palpable node in the neck were the major physical findings. Laboratory examinations revealed hypercalcemia and elevated levels of plasma parathyroid hormone (PTH) in a c-terminal assay. Nevertheless the levels of PTH found by a n-terminal assay disclosed an only small increase. The PTH levels were scarcely decreased after a bolous injection of calcium gluconate. A large tumor corresponding to the palpable node was resected. Histologically, the tumor was an adenoma with thick fibrous capsule and interparenchymal bands. Other parathyroid glands showed secondary clear cell hyperplasia without signs of cellular hyperactivity.
\end{abstract}

Secondary hyperparathyroidism in chronic renal failure is generally remarkable and prolonged stimulation of the hyperplastic glands may eventually provide autonomy in endocrine and cellular activities. Since the first description by St. Goar (1963) many cases of "tertiary hyperparathyroidism" have been reported. In most cases, however, it is probably a matter of semantics whether or not a particularly large nodule in hyperplasia is an adenoma.

The present paper concerns a case report of "tertiary hyperparathyroidism" with parathyroid adenoma in a patient with chronic renal failure treated with hemodialysis for 9 years.

Received December 4, 1981

\section{Case Report}

A 24-year-old man was admitted to the Division of Endocrinology, Department of Medicine, Wakayama Medical School Hospital with hypercalcemia.

Proteinuria was noted at the age of 10 and he was followed-up by a physician. After four years, he became uremic and was referred to the pediatric clinic of our hospital. At that time, the $\mathrm{RBC}$ was $236 \times 10^{4} / \mathrm{mm}^{3}$ and the WBC $2600 / \mathrm{mm}^{3}$. The plasma BUN was 88.5 $\mathrm{mg} / \mathrm{dl}$ and the creatinine $15.2 \mathrm{mg} / \mathrm{dl}$. The serum sodium and potassium were 131.5 $\mathrm{mEq} / \mathrm{L}$ and $4.65 \mathrm{mEq} / \mathrm{L}$, respectively. The calcium was $3.55 \mathrm{mEq} / \mathrm{L}$ and the phosphorus $6.2 \mathrm{mg} / \mathrm{dl}$. Ultrasonic studies of the kidneys 
revealed many cystic lesions. Management with hemodialysis was started in 1972. After nearly 9 years of regular hemodialysis performed in another hospital, he returned to our hospital with a fracture of the right femoral bone in June, 1980. Hypercalcemia and marked osteodystrophy was noted. There was no history of urinary stones. His brother had died of chronic renal failure at the age of 18.

On examination, he appeared pale. The tips of the fingers were clubbed. There were small prominences like richitic rossary on his chest. A thumbhead-size node was palpable at the left side of the neck. The lungs and the heart were normal. No hepatomegaly or splenomegaly was found. The RBC was $176 \times$ $10^{4} / \mathrm{mm}^{3}$ and the WBC $3200 / \mathrm{mm}^{3}$ with normal differential counts. The plasma BUN and creatinine levels before hemodialysis were $43 \mathrm{mg} / \mathrm{dl}$ and $5.7 \mathrm{mg} / \mathrm{dl}$, respectively. The serum calcium was $6.3 \mathrm{mEq} / \mathrm{L}$, phosphorus $4.7 \mathrm{mg} / \mathrm{dl}$ and the alkaline phosphatase 1710 $\mathrm{mU} / \mathrm{L}$ (Bessey-Lowrey method). X-ray films of bones revealed features of marked resorption; so-called renal osteodystrophy (Fig. 1, A). There was a fracture at the right femoral head. The scintigraphy of the parathyroid
Table 1. Calcium infusion test

\begin{tabular}{llccl}
\hline & 0 & 60 & 120 & $180 \mathrm{~min}$ \\
\hline C-PTH & 4.7 & 4.4 & 3.7 & $3.5 \mathrm{ng} / \mathrm{ml}$ \\
N-PTH & 0.230 & - & - & $0.185 \mathrm{ng} / \mathrm{ml}$
\end{tabular}

Twenty milliliters of calcium gluconate solved in distilled water $(3.5 \mathrm{mg} \mathrm{Ca} / \mathrm{Kg} \mathrm{B.W.}$ ) was administrated intravenously over a five-minute period.

glands showed a hot area on the left side of the neck corresponding to the palpable node. The parathyroid hormone (PTH) levels were $4.9 \mathrm{ng} / \mathrm{ml}$ in c-terminat assay (C-PTH: normal range below $0.5 \mathrm{ng} / \mathrm{ml}$ ) and $0.23 \mathrm{ng} / \mathrm{ml}$ in $\mathrm{n}$ terminatassay (N-PTH: normal range $0.18 \pm$ $0.01 \mathrm{ng} / \mathrm{ml}$, non-detectable in $37.5 \%$ ). The levels of PTH, both C-PTH and N-PTH, were scarcely decreased after bolous injection of calcium gluconate (Table 1). Administration of predonisolone in a dose of $40 \mathrm{mg} /$ day for 7 days failed to correct the serum calcium and phosphorus levels.

Exploratory surgery was performed. All of four parathyroid glands were enlarged and the left upper gland gave rise to a large tumor. Subtotal parathyroidectomy was performed. Their weights were as follows; the left upper

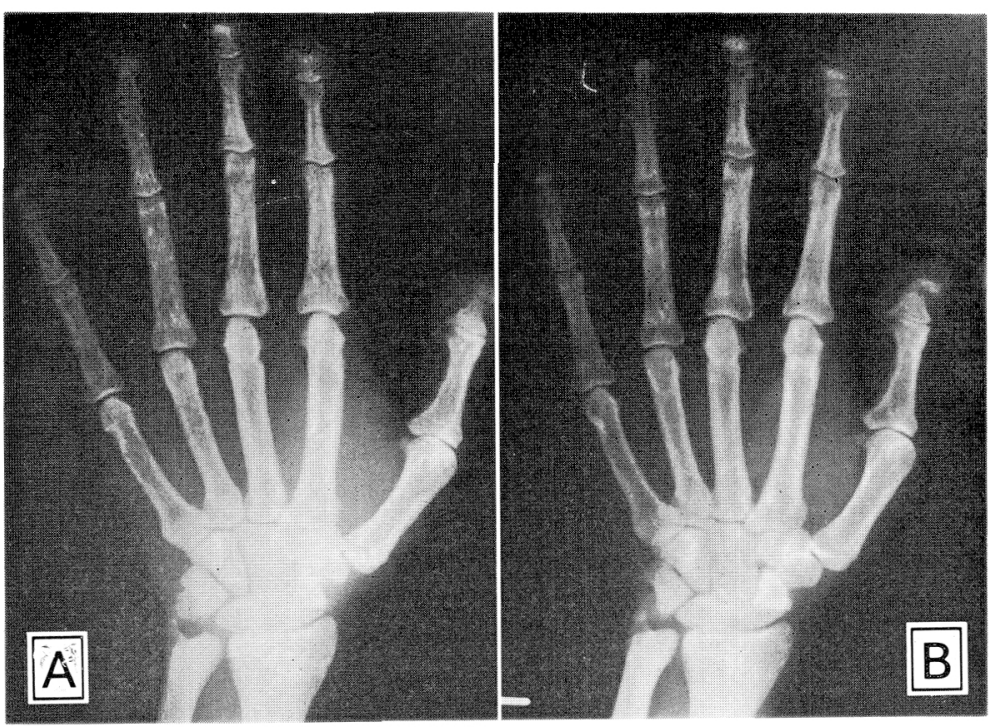

Fig. 1. X-ray pictures of finger bones. $\mathrm{A}$; just before parathyroidectomy. B; approximately 1 year after subtotal parathyroid resection. Note the disappearance of subperiosteal bone resorption and manifestation of osseous trabeculae after operation. Pseudoclubbing can be seen in both pictures. 

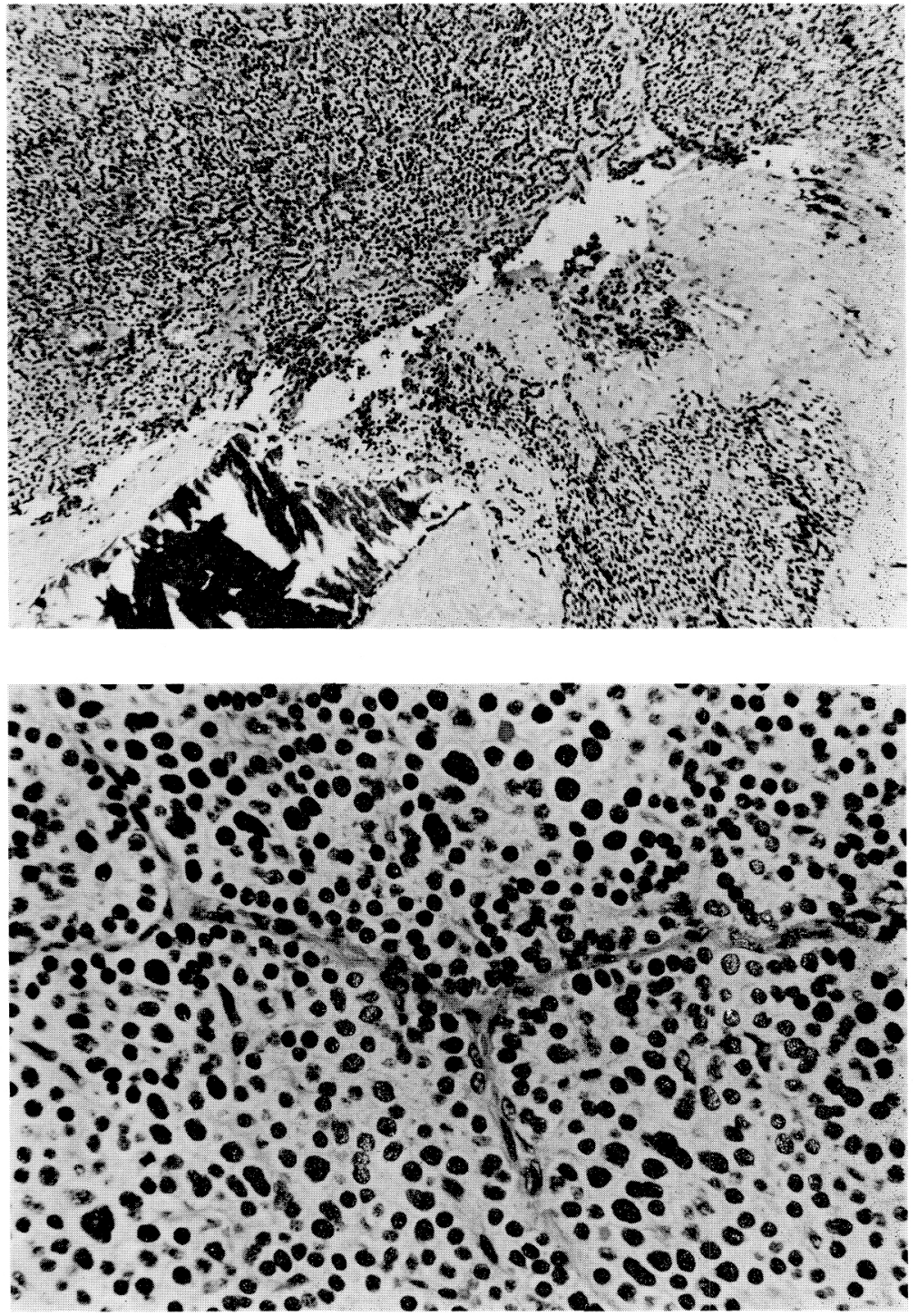

Fig. 2. Thick fibrous bands containing a calcified mass irregularly separate the neoplastic parathyroid tissue. (hematoxylin and eosin, $\times 65$ )
Fig. 3. The adenoma has large nuclei but no mitotic figures in sheet-like proliferation. (hematoxylin and eosin, $\times 250$ ) gland $4500 \mathrm{mg}$, the left lower $450 \mathrm{mg}$, the right upper $70 \mathrm{mg}$ and the right lower $200 \mathrm{mg}$. Histologically, the left upper tumor showed multinodular lesions which were generally covered with a fibrous capsule and individually separated by thick fibrous bands (Fig. 2). Foci of calcification were detected. Numerous hemosiderin granules suggested previous hemorrhage. Most of the tumor cells were small and grew in sheets and rossets. In certain areas they had nuclear pleomorphism and others invaded the capsule. The above findings may suggest malignancy. However, unquestionable findings of carcinoma consisting of a trabecular patterns of cytoplasma-rich cells as well as mitotic figures were not confirmed (Fig. 3). A rim of atrophic parenchym was attached to the capsule. The final histological diagnosis was adenoma. The remaining parathyroid glands had similar histologic findings to one 


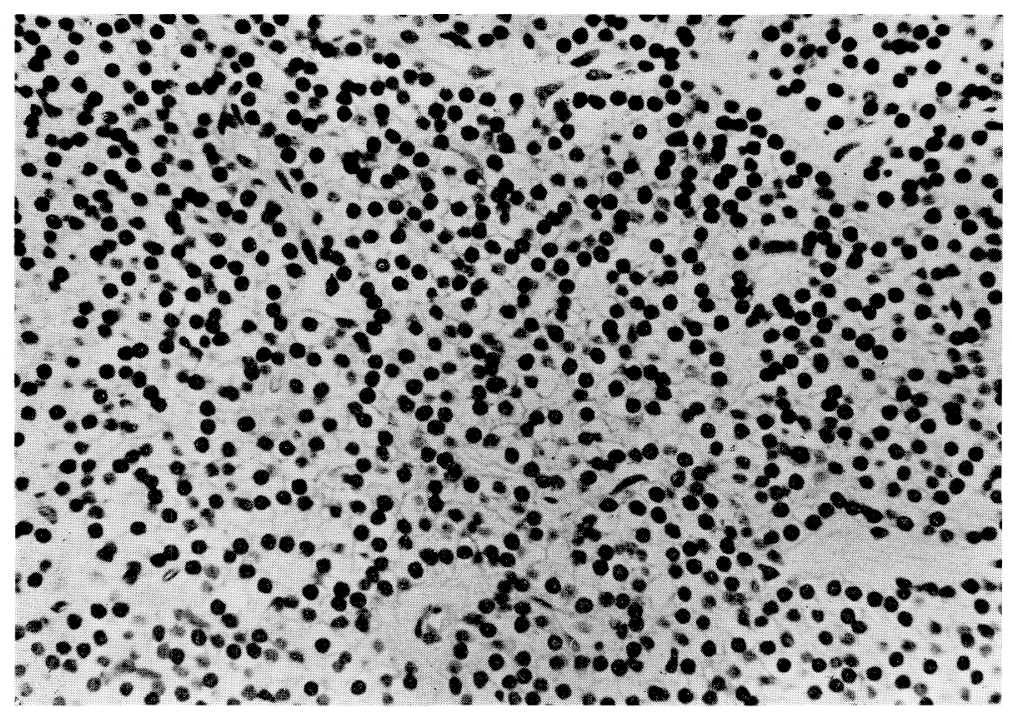

Fig. 4. A parathyroid gland opposite the site of the adenoma is composed of clear cells with uniform small round nuclei. (hematoxylin and eosin, $\times 250$ )

another. They were composed of rather small, uniform clear cells. The nuclei were small and all about the same size (Fig. 4). Histological diagnosis was slight hyperplasia without signs of hyperactivity.

After operation the serum calcium and plasma PTH levels fell immediately. Two days after operation, the calcium level was 3.99 $\mathrm{mEq} / \mathrm{L}$ and the patient was given calcium gluconate because of mild tetany. The CPTH levels on the fourth and sixth postoperative day were $1.6 \mathrm{ng} / \mathrm{ml}$ and $0.9 \mathrm{ng} / \mathrm{ml}$, respectively. For about one month after operation he often complained of mild convulsions and recovered each time following the administration of calcium gluconate. One month after the operation the serum calcium level was $4.2 \mathrm{mEq} / \mathrm{L}$ and the phosphorus 1.6 $\mathrm{mg} / \mathrm{dl}$. The level of C-PTH was $0.3 \mathrm{ng} / \mathrm{ml}$ and N-PTH undetectable. The oral administration of calcium lactate and $1 \alpha$-hydroxycholecalciferol $\left(\alpha-D_{3}\right)$ was effective in relieving the tetany. Approximately one year after parathyroidectomy, the serum calcium levels returned to the normal range and he no longer had episodes of convulsions. X-ray films of the finger bones no longer showed signs of subperiosteal bone resorption and osseous trabeculae became clear (Fig. 1, B). However, the fractured right femoral bone was not repaired.

\section{Discussion}

Certain authors (Lee et al., 1955; Goldberg and Torack, 1960; Chodack et al., 1962) reported cases of parathyroid adenoma developed in secondary hyperplasia due to longstanding renal failure. The term of "tertiary hyperparathyroidism" to describe such cases was introduced by St. Goar (1963) in the Case Record of the Massachusetts General Hospital.

Regarding the concurrence of hyperplasia and neoplasm of the parathyroid glands, Golden et al. (1965) studied six patients with this combination. They classified the disease into three groups: (1) primary renal disease with secondary parathyroid hyperplasia and subsequent autonomous adenoma formation, (2) primary parathyroid adenoma leading to renal insufficiency and secondary hyperplasia of remaining parathyroid glands, and (3) primary parathyroid hyperplasia with subsequent parathyroid neoplasia. In our case, evidence of hypocalcemia and hyperphos- 
phatemia in the early stage of renal failure ruled out the preexistence of parathyroid adenoma. It is, therefore, unquestionable that adenoma developed during the 9 years of hemodialysis for chronic renal failure. The fact that there was no sign of cellular hyperactivity in the hyperplastic glands also indicates the development of adenoma in tertiary hyperparathyroidism.

It is most important to make a clear distinction between adenoma and hyperplasia, especially in tertiary hyperparathyroidism. In general, however, it is difficult to clearly distinguch adenoma from hyperplasia in endocrine organs. Although some exceptional cases have been reported (Black and Utley, 1967; Lawrence, 1977), the presence of a rim of normal parathyroid tissue adjacent to a nodule has often been used as a criterion in the diagnosis of an adenoma. We confirmed this in our case. On the other hand, Schantz and Castleman (1973) studied 70 cases of parathyroid carcinoma and stated that the principle histological features that distingush carcinoma from adenoma should be a trabecular pattern, mitotic figures, thick fibrous bands, and capsular and blood vessel invasion. In our case, we found a few features such as thick fibrous capsule and bands separating the parenchym and capsular invasion as well. However, mitotic figures, the single most valuable criterion of carcinoma, were few. A trabecular pattern was missed. The tumor in this case, therefore, was diagnosed as an adenoma.

The elevation of the serum calcium level is frequently observed in chronic renal failure treated with hemodialysis for many years and this is not an only indicator of tertiary hyperparathyroidism. Indeed, Somerville et al. (1975) found two patients with hypercalcemia whose parathyroid glands were hyperplastic, not adenomatous. They claimed that the term of tertiary hyperparathyroidism is convenient and sounds precise but is often misleading. Therefore, most cases can be regarded as "secondary hyperparathyroidism with hyper- calcemia". Certain investigators (Parfitt, 1969; Vosik et al., 1972) also stated that the autonomy of the parathyroid glands in renal failure is related more to the mass of the tissue than to adenoma formation alone.

The levels of plasma PTH may be another indicator of the presence of a superimposed adenoma (Arnaud, 1973). The PTH levels, however, may be an unreliable guide since there is a degree of heterogeneity of immunoreactive PTH that has various metabolic activity and the degradation process. In our case, the plasma C-PTH levels were elevated but the levels of N-PTH suggesting a biologically active component were not so elevated. This discrepancy may result from the difference in the biological clearance rate.

The case described in the Case Record of the Massachusetts General Hospital (1963) was parathyroid adenoma and secondary hyperplasia of other parathyroid glands. The case under discussion in the present paper seemed to have been "true" tertiary hyperparathyroidism, and, to our knowledge, was the first to be described as tertiary hyperparathyroidism in Japan.

\section{Acknowledgements}

We are thankful to Dr. A. Uezu, Division of Gerontology, Department of Internal Medicine, Wakayama Medical School, for measuring the N-PTH levels.

\section{References}

Arnaud, C. D. (1973). Hyperparathyroidism and renal failure. Kidney Int. 4, 89-95.

Black, W. C. III and J. R. Utley (1968). The differential diagnosis of parathyroid adenoma and chief cell hyperplasia. Am. J. Clin. Pathol. 49, 761-775.

Chodack, P., H. Derman and A. R. Kantrowitz (1962). Primary hyperparathyroidism and coexistent renal lesion: Some diagnostic radiologic features. $N$. $Y$. State J. Med. 62, 3615-3627.

Goldberg, E. and R. M. Torack (1960). Combined primary and secondary hyperparathyroidism: Two case reports and a review. Ann. Intern. Med. 52, 87-101.

Golden, A., J. J. Canary and D. M. Kerwin (1965). 
Concurrence of hyperplasia and neoplasia of the parathyroid glands. Am. J. Med. 38, 562-578.

Lawrence, D. A. S. (1977). A histological comparison of adenomatous hyperplastic parathyroid glands. J. Clin. Pathol. 31, 626-632.

Lee, C. M., W. T. McElhinney and E. A. Gall (1955). Unusual manifestation of parathyroid adenoma. Arch. Surg. 71, 475-485.

N. Engl. J. Med. (1963). Case records of the Massachusetts General Hospital. 268, 943-953.

Parfitt, A. M. (1969). Relation between parathyroid cell mass and plasma calcium concentration in normal and uremic subjects: A theoretical model with an analysis of the concept of autonomy, and speculations on the mechanism of parathyroid hyperplasia. Arch. Intern. Med. 124, 269-273.

Schantz, A. and B. Castleman (1973). Parathyroid carcinoma: A study of 70 cases. Cancer 31, 600-605.

Somerville, P. J., D. J. Tiller and R. A. Evans (1975). What is tertiary hyperparathyroidism? Aust. N. Z. J. Med. 5, 551-556.

Vosik, W. M., C. F. Anderson, W. P. Steffffee, W. J. Johnson, C. D. Arnaud and R. S. Goldsmith (1972) Successful medical management of osteitis fibrosa due to "tertiary" hyperparathyroidism. Mayo Clin. Proc. 47, 110-113. 